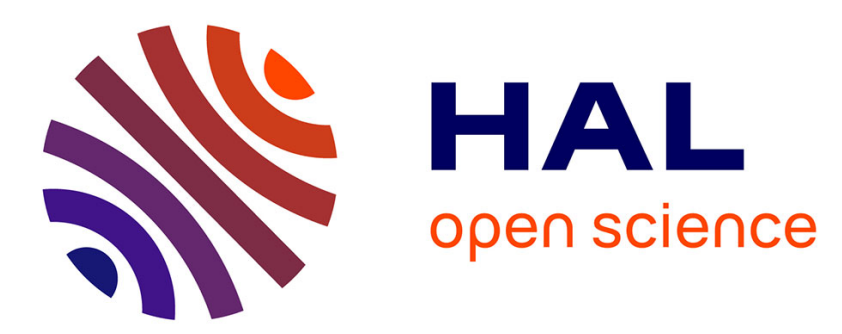

\title{
Costs and benefits of colony size vary during the breeding cycle in Black-headed Gulls
}

\author{
Guillaume Péron, Jean-Dominique Lebreton, Pierre-André Crochet
}

\section{To cite this version:}

Guillaume Péron, Jean-Dominique Lebreton, Pierre-André Crochet. Costs and benefits of colony size vary during the breeding cycle in Black-headed Gulls. Journal für Ornithologie $=$ Journal of Ornithology, 2010, 151 (4), pp.881-888. 10.1007/s10336-010-0526-8 . hal-00584728

\section{HAL Id: hal-00584728 \\ https://hal.science/hal-00584728}

Submitted on 10 Apr 2011

HAL is a multi-disciplinary open access archive for the deposit and dissemination of scientific research documents, whether they are published or not. The documents may come from teaching and research institutions in France or abroad, or from public or private research centers.
L'archive ouverte pluridisciplinaire HAL, est destinée au dépôt et à la diffusion de documents scientifiques de niveau recherche, publiés ou non, émanant des établissements d'enseignement et de recherche français ou étrangers, des laboratoires publics ou privés. 
TITLE PAGE

\section{Short title:}

Colony size effects on reproductive success

Title:

Costs and benefits of colony size vary during the breeding cycle in Black-headed Gulls Chroicocephalus ridibundus

Authors' names:

Guillaume Péron ${ }^{(1)}$

Jean-Dominique Lebreton ${ }^{(1)}$

Pierre-André Crochet ${ }^{(1)}$

\section{Authors' address}

${ }^{(1)}$ Equipe Biométrie et Biologie des Populations-Centre d'Ecologie Fonctionnelle et Evolutive-CNRS UMR 5175-1919 Route de Mende-34293 Montpellier, France

\section{Corresponding author:}

Guillaume Péron

Email: guillaume.peron@cefe.cnrs.fr 


\begin{abstract}
We studied the effects of colony size on individual reproductive success in a multisite population of Black-headed Gulls where colony size ranged from 10 to 5000 pairs. By focusing on family size, the number of chicks attended by individually marked parents, and accounting for between-individual variation, we detected a negative colony-size effect during the very first days of life of the chicks that was compensated by a subsequent increase in the proportion of surviving chicks with colony size. We suggest that this result originates in the interplay between overcrowding costs acting on hatching success, and benefits of colonial breeding, most probably more efficient food-searching (foraging enhancement), acting on chicks' survival. However, the frequency of complete colony failure increased with decreasing colony size. Taking this hazard risk into account yielded a corrected estimate of the effect of colony size on breeding success, and indicated that the largest colonies were the most productive. This pattern is congruent with the previous finding that larger colonies are more attractive to dispersing breeders.
\end{abstract}

\title{
Key-words:
}

Breeding success; Chroicocephalus ridibundus; Coloniality; Density-dependence; Fecundity; Larus. 


\section{Introduction}

2 Colonial breeding (breeding in high-density sites exempt of feeding resources with territories

3 limited to the nest area) is quite widespread in birds and especially in seabirds. One of the

4 striking patterns is the sheer variation that exists in colony size. A recurrent question among

5 ornithologists is whether this variation simply reflects variation in ecological conditions

6 (distribution of resources, availability of nest sites, etc.) or whether the choice to settle in a

7 colony of a given size is a trait subject to selection. These questions are generally addressed

8 by studying variation in reproductive success $(R S)$, which appears to be a useful metric to

9 study the fitness consequences and ecological correlates of colony size (but see Danchin and

10 Wagner 1997).

In colonial birds, especially in Charadriiforms, provisioning rate is often considered

12

13

14

15

among the main determinants of reproductive success (Uttley et al. 1994; Jodice et al. 2006;

see also Graves et al. 1984; Hamer et al. 1993; Sadoul et al. 1996; van Dijk et al. 2009).

Provisioning rate depends on foraging success, which is known to be enhanced via

information exchange between conspecifics foraging in the same area (Ward and Zahavi

1973; Clark and Mangel 1984; Richner and Heeb 1995; Brown and Bomberger Brown 1996;

see further detail in the discussion section). Provisioning rate is therefore expected to increase with conspecific density on the foraging grounds (Pöysa 1992), and, as the density of foraging individuals increases around large colonies (Brandl and Gorke 1988), we expect an enhanced reproductive success in large colonies. However, some studies indicate the opposite effect, i.e., that competition forces individuals from large colonies to travel further and longer to find food than individuals from small colonies (Lewis et al. 2006), sometimes to the point where colony size negatively impacts on body condition of both adults and chicks (Santema et al. 2009). Furthermore, competition is only one of the known or supposed costs of breeding in large colonies. These costs also include higher rate of transmission of disease and parasites, 
higher levels of aggression and antagonistic behaviours, etc. (Brown and Bomberger Brown 1996; Danchin and Wagner 1997).

It is thus not surprising that, among the large number of studies reviewed by Brown and Bomberger Brown (1996, p321-323), every pattern of variation in $R S$ with colony size can be found, from no effect to a directional trend for a benefit to the largest or smallest colonies through a non linear effect with an optimal colony size. This variation among studies suggests that $(i)$ the costs and benefits of colonial breeding are not the same in different systems and/or (ii) the observed patterns depend on the $R S$ variable used and on the stage of the breeding season that is under study (proportion of failed nests, average clutch size, average number of fledglings per breeding pair, fledgling survival, etc.).

Our aim in this paper is to contribute to these debates by studying colony size effects on $R S$ in a Black-headed Gull Chroicocephalus ridibundus (BHG) multisite population presenting a contrasted distribution of colony sizes. Indeed a single, large colony concentrated most pairs and increased in size during the study period (from around 2000 to around 5000 pairs), whereas several small colonies (numbering on average 163 pairs \pm 171 ) decreased in both number and total size. More precisely, we examined (i) how the costs and benefits of colony size interacted throughout chicks' development and (ii) whether a potential cost of breeding in small colonies could have driven the aggregation of breeders in the largest colony. Although BHG are known to occasionally breed as solitary pairs there was no such record in the dataset. We therefore did not contrast solitary vs. colonial breeding in this study but we investigated the costs/benefits of colony size.

The data we used for that purpose was the family size, i.e. the number of chicks attended by individually-marked parents. By using its variation with chicks' age, we had access to two variables for $R S$ : 
- the initial family size (IFS), which was considered as a proxy for the hatching success and chicks' survival during the first few days,

- the decrease in family size with age (DFS), which was considered as a proxy for chicks' survival rate during growth and until fledging. By using this variable instead of the family size just before fledging, we were able to use all the records of family size between hatching and fledging, hence to increase the sample size.

Predicting how IFS and DFS should vary with colony size in our BHG population required a few assumptions to be made on the main processes at stake. First, overcrowding costs in BHG are of three main kinds: increase in the level of competition for the access to high, secure nest locations, increase in alarm flight frequency and duration, and increase in antagonistic behaviours. Eggs and young chicks are supposedly more sensitive to these costs than older chicks: they can fall in the water or be predated from low, unsafe nests, they can die because of poor thermoregulation during alarm flights and they can suffer from aggression by neighbouring adults. In short, we assumed that overcrowding costs should impact more on IFS (eggs and young chicks) than on DFS (older chicks).

Second, the food resource available to chick-raising parents can vary with colony size, either positively through foraging enhancement, or negatively through density-dependence. If we make the assumption that food resource during the breeding season does not impact on clutch size and hatching success, we can predict that DFS but not IFS should be impacted by colony size effects on food resource (BHG as capital breeders, Drent \& Daan 1980; Hamer et al. 1993 in another Larid species, but see Thyen and Becker 2006 and further details in the discussion section). Overall from the two preceding points we thus predict that IFS should decrease with colony size and that DFS should increase with colony size.

Third, predation risk is expected to decrease with colony size, due to among others the dilution effect (Hamilton 1971) and early-warning effect (Lazarus 1979). An increase with 
colony size in the efficiency of anti-predator behaviours (mobbing) also likely occurs (Allainé 1991).Predators' distribution can, however, alter these predictions. (i) If predators are strongly localised (territorial, dependent on rare habitat features...), the associated risk can eventually be independent of colony sizes. (ii) Alternatively, predators can concentrate their attacks on the densest sites where preys may appear more available (Larivière and Messier 1998). These simple predictions can be further complicated by environmental stochasticity due to climatic accidents (Aebischer 1993), human perturbations (Calado 1996) or predatordriven failures (Ratcliffe et al. 2008). For example, climates partially drives the $R S$ of Fulmarus glacialis (Lewis et al. 2009), which would probably have modified the effect of colony size in that system. In our BHG population, whole-colony failures, i.e. the desertion of a given colony before fledging, are relatively frequent (Table 1) and constitute a major external driver of $R S$. Their causes include man-driven droughts of the ponds and perturbations by terrestrial predators (Lebreton and Landry 1979). We further suggest that once a threshold proportion of breeders have failed, the remaining pairs desert the colony as well. The threshold proportion is supposedly more easily reached in small colonies (e.g., a single wildboar Sus scrofa will destroy most nests in a 100-pair colony, but its impact will be less visible in a 4000-pair colony). Thereby the risk of whole-colony failure should decrease with colony size, providing an advantage for breeding in large colonies. We combined the results from the family size data introduced above with an estimate of the probability of whole-colony failure. This made it possible to correct the estimate of $R S$ for the occurrence of such failures and see how they affect the relationship between colony size and $R S$ during the early and late parts of the breeding cycle. 


\section{Methods}

Study site and species

The study site is located in the Forez basin, Loire department, central France. Each year between 1978 and 2008, from 9 to 34 colonies (mean 19.9) of BHG bred in man-made ponds situated in a farmland mosaic (see Lebreton 1987 for a more complete description of the study area). Gulls lay a clutch with a modal size of three eggs from mid-April to the beginning of June (Lebreton and Landry 1979). Chicks and adults have been ringed since 1978.

One of the colonies (La Ronze) differed from other colonies due to its size (between 2000 and 5000 pairs), while the other colonies numbered on average 163 pairs (SD: 171). Also, between 1978 and 2006 La Ronze was occupied continuously, contrary to smaller colonies which experienced either spontaneous desertion by the gulls and/or temporary man-induced perturbations that prevented breeding (droughts for management purpose). In 2007 La Ronze experienced such a drought; in 2008 the colony reappeared on that pond but numbered only 500 pairs.

\section{Data collection}

\section{-Family size data}

Each year between 1979 and 2008 a subset of the active colonies (depending on access authorizations) was visited to look for ringed birds. We collected data simultaneously in La Ronze and in the smaller colonies but due to colony-specific laying dates more time was devoted to the large colony early in the season relative to small colonies. Field work lasted usually four or five weeks, between May 5 at the earliest and June 28 at the latest. However, data collection in the small colonies began only from 1995 onwards, with only a few sparse records before that year (see Table S1 in Appendix for details on when and where data were collected). We opportunistically recorded family size of individually-marked adult birds (metal rings on tibia) at various stages of the chicks' development while moving through the 
colonies in a floating blind (Lebreton 1987). The number of chicks per pair (= the family size) was counted when the parents were feeding the chicks. Chicks' age in days was estimated with an accuracy of 2 to 4 days through detailed observation of size and plumage development (Lebreton and Landry 1979). As families were recorded while looking for ringed parents, it is unlikely that family size influenced on the detection probability of families. Of course, only families with at least one chick could be recorded (thereby excluding failed breeding attempts).

$$
\text { - Colonies' average } R S
$$

Each year, we visited most of the colonies at least twice (installation period and end of breeding cycle), including those that were not surveyed for family sizes. We recorded the number of pairs (colony size) and the colonies' average $R S$, quantified using a three-level index: 0 (no fledgling produced), 1 (low success), 2 (high success). Whole-colony failure is hereafter the occurrence of a ' 0 '. This protocol provided us with an estimate of the proportion of birds that tried to breed even if they failed early and did not enter our dataset on family size.

\section{Model for the family size data}

The dataset included 1,255 family size records from 966 individually-marked birds over 31 years (Fig. 1). This dependent variable was worth 1, 2 or 3 (with a few marginal records of 4-chicks families possibly, but not compulsorily, due to chick adoption or intraspecific clutch parasitism). Generalized linear mixed models (GLMM) with Poissondistributed error terms and log link function were fitted using the restricted maximum likelihood (REML) method implemented in the macro GLIMMIX in SAS 9.1.

We included the fixed effects of chicks' age, colony size and their interaction. Theoretically, the effect of colony size is not thought to be linear (see Clark and Mangel 1984; Forbes and Kaiser 1994), which was taken into account via a log-transformation of 
147 colony sizes. Similarly, chicks' death rate is expected to decrease with age, advocating the 148 log-transformation of chicks' ages also. We corrected for the potential confounding effects of

149 between-individual (966 individuals), -year (31 years) and -site (10 sites) variation with

150 independent (i.e., non-nested) random effects. Temporal autocorrelation was accounted for

151 using a first order autoregressive structure.

A large number of observers contributed to the data, but one of us (J.D.L.) contributed much more than other observers (collecting more than half of the data) and spent more time in

154 the LR colony than other observers, but less time in the small colonies. Because old chicks are very mobile around their nest site, our method relied on a certain amount of subjectivity to

156 decide when a family size had been accurately determined, suggesting non-negligible

157 observer effect. We thus accounted for the observer effect with a fixed effect. Preliminary

158 analyses indicated that contrasting J.D.L.to all other observers captured most of the between159 observer variation.

160 We expected a low statistical power due to sparse data in several colony size $\times$ chicks' 161 age cells. Statistically significant fixed effects were considered to be those whose confidence

162 interval (CI) did not encompass zero. For the random effect structure we used the Akaike

163 Infromation Criterion (AIC) to discard non-significant effects.

164 Model for the whole-colony failure data

165 We built a GLMM with binomial error term and logit link function, with occurrence of 166 whole-colony failure as dependent variable and colony size as fixed effect, colony identity 167 and year as random effects (with a temporal autocorrelation structure), using the restricted 168 maximum likelihood (REML) method implemented in the macro GLIMMIX in SAS 9.1. This

169 model produced an estimate of the probability of colony failure depending on colony size.

170 Statistical significance of the effects was determined as in the previous section. 
Assuming independence between family size data and whole-colony failure data, and in order to obtain a model of $R S$ accounting for colony size effects on both family size and the frequency of whole-colony failures, we multiplied the predictions from the two models constructed above. Confidence intervals on this expected $R S$ were computed using a multiple (1000 times) resampling procedure, using the standard errors estimated at the previous stage to compute an expected distribution of models' parameters.

\section{$177 \quad$ Results}

178 Model for the family size data Fixed effects of colony size, chick's age and their interaction all had confidence

180 intervals only marginally encompassing zero, and were thus maintained in the final model

181 (Table 2). Concerning random effects, year (with autoregressive structure) and individual 182 effects proved significant with regards to AIC. The GLMM revealed an important variation 183 between individuals: parent identity accounted for $20.4 \%$ of the total variance in the data.

184 Year effect was much lower (2.3\% of the total variance). Table 2 gives details of the

185 estimated parameter values in the final model. The statistically significant effect of colony

186 size indicates that IFS (family size shortly after hatching) decreased with colony size (Fig. 2).

187 This is partly compensated by a decrease in DFS (chick mortality) with colony size

188 (interaction term in Table 2; Fig. 2). Observer effects are presented in Table S2 in Appendix;

189 they were discarded due to statistical non-significance.

190 Model for the whole-colony failure data.

191 As expected from an examination of the raw data (Table 1) the probability of complete

192 colony failure markedly decreased with increasing colony size (Table 3: fixed effect), even

193 after controlling for the colony identity and year using random effects. Concerning random

194 effects, the GLMM revealed a significant variation between years: year accounted for 32.8\%

195 of the total variance in the data. Random effect of colony identity was discarded by AIC. The 
temporal autocorrelation of colony failure probability appeared non-significant with regard to

197 AIC and autoregression coefficient estimate.

198 Combining the two models.

199 The "composite" model of $R S$ obtained by multiplying the predicted family size at 200 fledging in successful families (from the model in Table 2) and the predicted probability of

201 whole-colony failure (from the model in Table 3) suggested a strongly detrimental effect of 202 breeding in colonies of 100-200 pairs or less but little effect of colony size on $R S$ for colony 203 size above 300 pairs (Fig. 3).

\section{Discussion}

205 Colony size effects on initial family size

206 Our first hypothesis (colonial breeding is costly at the egg and young-chick stages) is verified 207 by the fact that IFS decreased with colony size. Given that the most abundant predators

208 (Carrion Crow Corvus corone, medium-sized raptors such as Black Kite Milvus migrans, 209 herons, snakes, Canids, Mustelids) prey mostly on eggs or young chicks, explaining this result 210 by predation risk reduction would imply that small colonies are less subject to predation, 211 which seems improbable (Hamilton 1971; Lazarus 1979; Allainé 1991), unless they attract 212 less predators (Larivière and Messier 1998).

A second hypothesis is that females in large colonies have access to fewer resources

214 and thus produce less and/or poorer-quality eggs than females in small colonies. Yet in the 215 introduction we relied on the assumption that, at the egg-laying stage, females use mostly 216 resources secured before settling in the colonies. This assumption that BHG are capital 217 breeders (Drent and Daan 1980) is however contradicted by Thyen and Becker (2006) who 218 found that in another BHG population clutch size changes with weather conditions during the breeding season. 
A third explanation (that we consider the most likely) is that the larger the colony, the more intense the risk that eggs and young chicks are lost during alarm flights or during intense antagonistic behaviours. Here we thus assume that colony size and nest density are correlated (which seems relevant due to the much smaller variation in pond area compared to colony sizes). This is confirmed by our own observations (although no quantitative data are available yet) of more numerous fights among neighbours in large colonies and of occasional loss of eggs or small chicks during or after alarms because of such fights, or as small chicks that leave the nest during alarms are often attacked by neighbours when they cross their territories.

Even if we are unable to firmly choose among the potential explanations (resource

230 limitation at the laying stage or increased loss of eggs and small chicks), our result that IFS decreases with colony size at least indicates that, at the egg-laying stage, overcrowding costs exceed any benefit of colony size.

Colony size effects on the decrease in family size with chicks' age Our second prediction, that DFS decreases with colony size, is supported by the interaction between colony size- and chicks' age- effects. This interaction indicates that for each family the proportion of hatched chicks that survives to fledging increases with colony size. Any mechanism increasing chick survival but not hatching success can explain these results, and 238 we consider here predation risk reduction and foraging enhancement.

240 early-warning effect (Lazarus 1979). An increase with colony size in the efficiency of anti241 predator behaviours (mobbing) also likely occurs (Allainé 1991), thereby allowing individuals

242 from large colonies to spend more time in other chick-care activities. However in the 243 predation risk reduction scenario it seems hard to elucidate why the benefits act more on old 244 chicks (DFS) than on eggs and very young chicks (IFS). 
Foraging enhancement is therefore a more likely hypothesis explaining the observed increase in chicks' survival with colony size. Congruent with this consideration is the fact that the exchange of food information has been demonstrated in our study species (Andersson et al. 1981) as well as in a closely related species that has similar feeding habits (Evans 1982).

These two studies are to our knowledge the only two testing the existence of information transfers in Chroicocephalus gulls. Social foraging is also suggested by the finding in our study population that neighbours in the largest colony tend to forage together (Prévot-Julliard and Lebreton 1999), and by the consideration that white plumage makes it possible to detect successful foragers at a great distance (Beauchamp and Heeb 2001). In the next paragraph we thus provide a few additional elements on foraging enhancement in the Forez BHG.

Locating food sources and foraging enhancement: a simplistic model

If there was one and only one feeding site available at any time, and if they were foraging individually, gulls would have to patrol their home range of size $\mathrm{S}$, at the speed $\mathrm{V}$ and with the detection distance $\mathrm{R}$. The instantaneous probability $\lambda$ that a lone bird without prior knowledge would find the feeding site is: $\lambda \approx 2 R V / S$. With the plausible values $\mathrm{S}=710 \mathrm{~km}^{2}$

260 (a circle of approx. 15km radius: Brandl and Gorke 1988), V = $11.3 \mathrm{~m} . \mathrm{s}^{-1}$ (Shamoun-Baranes and van Loon 2006) and $\mathrm{R}=500 \mathrm{~m}$, we obtain $\lambda \approx 0.057 \mathrm{~h}^{-1}$, which would mean that a lone bird needs on average 17.5 hours to find an appropriate feeding site. The selection pressure to enhance foraging efficiency would thus be high. If $\mathrm{N}$ birds looked for the same site, and neglecting the time needed for information transfers, the instantaneous probability that the field is found would be $\mathrm{N} \times \lambda$ (Clark and Mangel 1984).

We must admit that the assumption of the uniqueness of the feeding site is quite unlikely. Nevertheless, this simplistic model highlights the underlying idea that finding the best food possible (i.e., securing the highest ratio energy or nutriments brought back to the chicks vs. time or energy spent by the parents) takes too much time if foraging solitarily. 
270 Furthermore, information transfer can allow a rapid specialisation on the best available

271 resource at any time. We suggest information transfers as a possible explanation for our result

272 that chick survival increased with colony size.

273 Correcting for whole-colony failures

274 The family size at age 32 days corresponds to the number of fledglings per pair. Our results

275 indicated that, excluding complete breeding failures, BHG in our population produced

276 between 1.4 and 1.6 fledglings per pair depending on colony size (curve labelled "age 32" in

277 Fig. 2). This value lies in the high part of the range of reported values for BHG (0.3 to 2

278 fledglings per pair: Patterson 1965; Lebreton and Landry 1979; Viksne 1980; Thyen and

279 Becker 2006; van Dijk et al. 2009). This result is probably due to our not accounting for

280 reproductive failures (pairs that do not produce any fledgling on a given year).

Reproductive failures are partially accounted for when correcting the previous

282 estimates for the occurrence of whole-colony failures. The much more frequent occurrence of

283 whole-colony failures in small colonies (Table 1) is an additional cost of breeding in small

284 colonies, and it appears as the main determinant of the sharp decrease in expected $R S$ at low

285 colony sizes (Fig. 3). This low $R S$ in small colonies is congruent with previous results that

286 such colonies are less often chosen by dispersing experienced breeders (as opposed to

287 inexperienced breeders; Péron et al. 2009), and that breeders from small colonies are less site-

288 faithful than breeders from large colonies (Péron et al. submitted). Whether these results stem

289 from colony size per se or a correlation between size and "quality" remains debatable. The

290 result that whole-colony failure probability is neither temporally autocorrelated nor dependent

291 on colony identity suggests that whole-colony failures can be viewed as an external hazard,

292 i.e., independent of the true quality of the colony site. However in a low-quality habitat

293 individuals are expected to be less site-faithful which could be sufficient to maintain colonies

294 at a small size, and therefore colony size and colony quality could match exactly. 
Conclusion

The 32-year long BHG dataset that we studied illustrated that the various costs and

297 benefits of colony size varied during the breeding cycle, with costs exceeding benefits at the beginning of the cycle and benefits exceeding costs at the end of the cycle. Moreover the perturbation regime (environmental stochasticity) appeared as a main driver of breeding success and largely modified the final output of breeding in the various colony sizes, with the smallest colonies being the most exposed to perturbations. These findings put an interesting

302 light on the inconsistencies between previous studies (reviewed in Brown and Bomberger Brown 1996; see also Lewis et al. 2009; Santema et al. 2009). They suggest that unaccounted differences in the regime of perturbation might have flawed previous results. Any interaction between colony size and the regime of perturbation can be predicted, with increases in the rate of perturbation with colony size possibly stemming from predators' attraction towards aggregated prey items, and decreases possibly originating from a threshold mechanism, as is suggested in our system, or from small colonies being settled in lower-quality habitats (Forbes and Kaiser 1994). Eventually the estimates of RS along the colony-size gradient in our system provided an explanation for the observed dynamics of our population. It seems indeed likely

311 that individuals aggregated in the largest colony because this colony provided the best $R S$.

312 Density-dependent mechanisms did not counter-balance this benefit. Results concerning

313 breeding dispersal are in line with this consideration: colony size appears as a good predictor 314 of colony choice (Péron et al.2009).

\section{Zusammenfassung}

317 Kosten und Nutzen der Koloniegröße variiert während des Brutzyklus' von Lachmöwen

\section{Chroicocephalus ridibundus}


320 An mehreren Koloniestandorten einer Lachmöwen-Population wurden die Effekte der

321 Koloniegröße auf den individuellen Reproduktionserfolg untersucht. Die Koloniegröße lag

322 bei 10 bis 5000 Paaren. Bezogen auf die Familiengröße (die Anzahl der betreuten Küken

323 durch individuell markierte Eltern) und unter Berücksichtigung der interindividuellen

324 Variation, wurde ein negativer Effekt der Koloniegröße während der ersten Lebenstage der

325 Küken nachgewiesen. Dieser wurde kompensiert durch einen nachfolgenden Anstieg im

326 Anteil der überlebenden Küken bezogen auf die Koloniegröße. Als Grund dafür vermuten wir

327 die Wechselwirkung zwischen einem erhöhten Aufwand für den Schlupferfolg und die

328 Vorteile einer Koloniebrut sowie einer möglicherweise effizienteren Nahrungssuche

329 (Intensivierung der Nahrungssuche) für das Überleben der Küken. Allerdings erhöht sich die

330 Häufigkeit vollständiger Koloniemisserfolge bei abnehmender Koloniegröße. Die

331 Einbeziehung diese Risikos liefert eine verbesserte Abschätzung des Effektes der

332 Koloniegröße auf den Bruterfolg und zeigt, dass die größten Brutkolonien die produktivsten

333 sind. Dieses Muster entspricht vorherigen Ergebnissen, wonach größere Kolonien attraktiver

334 sind für sich ansiedelnde Brutvögel.

336 Acknowledgments

Thanks are due to all volunteers, students and researchers who contributed to the field

338 work. We are grateful to land owners who gave access to their properties. We thank in

339 particular J. Arquillère, Manager of La Ronze, for continuous support and help throughout

340 this study. T. Boulinier kindly offered helpful comments on a first draft of this article.

341 We are grateful to P.H. Becker, E.V.M. Stienen and an anonymous reviewer for improving

342 this article. 


\section{References}

Aebischer NJ (1993) Immediate and delayed effects of a gale in late spring on the breeding of the Shag Phalacrocorax aristotelis. Ibis 135: 225-232.

Allainé D (1991) The effects of colony size and breeding stage on colony defence pattern in the Black-headed Gull. Acta Oecol 12: 385-396.

Andersson M, Götmark F and Wiklund CG (1981) Food information in the Black-headed Gull, Larus ridibundus. Behav Ecol Sociobiol 9: 199-202.

Barta Z, Giraldeau LA (2001) Breeding colonies as information centers: a reappraisal of information-based hypotheses using the producer-scrounger game. Behav Ecol 12: 121127.

Beauchamp G, Heeb P (2001) Social foraging and the evolution of white plumage. Evol Ecol Res 3: 703-720.

Boulinier T, Danchin E (1997) The use of conspecific reproductive success for breeding patch selection in terrestrial migratory species. Evol Ecol 11: 505-517.

Brandl R, Gorke M (1988) How to live in colonies - Foraging range and patterns of density around a colony of Black-headed Gulls Larus ridibundus in relation to the gulls energy budget. Ornis Scand 19: 305-308.

Brown CR and Bomberger Brown M (1996) Coloniality in the Cliff Swallow. University of Chicago Press, Chicago, USA.

Calado M (1996) Little Tern (Sterna albifrons) status and conservation at Ria Formosa Natural Park, Algarve, Portugal. Colon Waterbird 19: 78-80.

Clark CW, Mangel M (1984) Foraging and flocking strategies - Information in an uncertain environment. Am Nat 123: 626-641. 
Danchin E, Wagner RH (1997) The evolution of coloniality: the emergence of new perspectives. Trends Ecol Evol 12: 342-347.

Drent RH, Daan S (1980) The prudent parent - Energetic adjustments in avian breeding. Ardea 68: 225-252.

Evans RM (1982) Foraging-flock recruitment at a Black-billed gull colony - implications for the information-center hypothesis. Auk 99: 24-30.

Forbes LS, Kaiser GW (1994) Habitat choice in breeding seabirds - When to cross the information barrier. Oikos 70: 377-384.

Graves J, Whiten A, Henzi P (1984) Why does the Herring Gull lay 3 eggs. Anim Behav 32: 798-805.

Grosbois V, Reboulet AM, Prévot-Julliard AC, Bottin L, Lebreton, J D (2003) Dispersion et recrutement chez la Mouette rieuse Larus ridibundus. Alauda 71: 139-144. In French.

Grünbaum D, Veit, RR (2003) Black-browed albatrosses foraging on Antarctic krill: Densitydependence through local enhancement? Ecology 84: 3265-3275.

Hamer KC, Monaghan P, Uttley JD, Walton P, Burns MD (1993) The influence of foodsupply on the breeding ecology of Kittiwakes Rissa tridactyla In Shetland. Ibis 135: 255263.

Hamilton, WD (1971) Geometry for the selfish herd. J Theor Biol 31: 295-311.

Jodice PGR, Roby DD, Turco KR, Suryan RM, Irons DB, Piatt JF, Shultz MT, Roseneau DG, Kettle AB, Anthony JA (2006) Assessing the nutritional stress hypothesis: relative influence of diet quantity and quality on seabird productivity. Marine Ecol-Prog Ser 325: 267-279.

Kadlec JA, Drury A (1968) Structure of New England Herring Gull population. Ecology 49: 645-676. 
Larivière S, Messier F (1998) Effect of density and nearest neighbours on simulated waterfowl nests: can predators recognize high-density nesting patches? Oikos 83: 12-20.

Lazarus J (1979) Early warning function of flocking in birds - experimental study with captive Quelea. Anim Behav 27: 855-865.

Lebreton JD (1987) Régulation par le recrutement chez la Mouette rieuse Larus ridibundus. Rev Ecol - Terre Vie Suppl. 4: 173-187. In French.

Lebreton JD, Landry P (1979) Fécondité de la mouette rieuse Larus ridibundus dans une colonie importante de la plaine du Forez (Loire, France). Le Gerfault 69: 159-194. In French.

Lewis S, Elston DA, Daunt F, Cheney B, Thompson PM (2009) Effects of extrinsic and intrinsic factors on breeding success in a long lived seabird. Oikos 118: 521-528.

Lewis S, Gremillet D, Daunt F, Ryan PG, Crawford RJ M, Wanless S (2006) Using behavioural and state variables to identify proximate causes of population change in a seabird. Oecologia 147: 606-614.

Patterson IJ (1965) Timing and spacing of broods in the Black-headed Gull Larus ridibundus. Ibis 107: 433-459.

Péron G, Lebreton JD, Crochet PA.(2009) Breeding dispersal in Black-headed Gull : the value of familiarity in a contrasted environment. J Anim Ecol. doi: 10.1111/j.13652656.2009.01635.x.

Pöysa H (1992) Group foraging in patchy environments - the importance of coarse level local enhancement. Ornis Scand 23: 159-166.

Prévot-Julliard AC, Lebreton, JD (1999) Spatial organization of foraging within a Blackheaded gull Larus ridibundus colony. Ibis 141: 144-149.

Prévot-Julliard AC, Lebreton JD, Pradel R (1998) Re-evaluation of adult survival of Blackheaded gulls (Larus ridibundus) in presence of recapture heterogeneity. Auk 115: 85-95. 
Ratcliffe N, Craik C, Helyar A, Roy S, Scott M (2008) Modelling the benefits of American Mink Mustela vison management options for terns in west Scotland. Ibis 150: 114-121.

Richner H, Heeb P (1995) Communal life: honest signaling and the recruitment center hypothesis. Behav Ecol 7: 115-119.

Rolland C, Danchin E, de Fraipont M (1998) The evolution of coloniality in birds in relation to food, habitat, predation and life-history traits: a comparative analysis. Am Nat 151: $514-528$.

Sadoul N, Johnson AR, Walmsley JG, Leveque R (1996) Changes in the numbers and the distribution of colonial Charadriiformes breeding in the camargue, southern France. Colon Waterbird 19: 46-58.

Santema P, Griffith SC, Langmore NE, Komdeur J, Magrath MJL (2009) Does foraging efficiency vary with colony size in the fairy martin Petrochelidon ariel? J Avian Biol 40: $57-66$.

Shamoun-Baranes J, van Loon E (2006) Energetic influence on gull flight strategy selection. J Exp Biol 209: 3489-3498.

Thyen S, Becker PH (2006) Effects of individual life-history traits and weather on reproductive output of Black-headed Gulls Larus ridibundus breeding in the Wadden Sea, 1991-97. Bird Study 53:132-141

Uttley JD, Walton P, Monaghan P, Austin G (1994) The effects of food abundance on breeding performance and adult time budgets of Guillemots Uria aalge. Ibis 136: 205213.

Valone TJ, Giraldeau LA (1993) Patch estimation by group foragers - What information is used. Anim Behav 45: 721-728.

van Dijk JGB, Stienen EWM, Gerritsen S, Majoor FA (2009). Reproductie van de Kokmeeuw Larus ridibundus in kust- en binnenlandkolonies. Limosa 82: 13-22. In Dutch. 
Viksne J (1980) Some problems in Black-headed Gull Larus ridibundus research and the necessity of international cooperation in this respect. Acta Ornithol 17: 71-80.

Ward P, Zahavi A (1973) Importance of certain assemblages of birds as information-centers for food-finding. Ibis 115: 517-534. 


\section{Figures' legend}

Fig. 1: Family size, chicks' age and colony size: raw data presentation (circle size represents the number of occurrences of a given family size). Colony size is the number of breeding pairs in the colony and chicks' age is in days since hatching. A: Chicks younger than 7 days. B: Chicks older than 24 days. Chicks fledge at 32 days on average. For clarity, colony size is presented in three classes (1-1000 pairs, 1001-2500 pairs and 2501-5000 pairs). Family size is the number of chicks per pair.

Fig. 2: Family size, chicks' age (in days) and colony size (in pairs): estimations of the GLMM. Family size is the number of chicks per pair. Chicks fledge at 32 days on average. The insert is a 3D representation of the same model.

Fig. 3: Post hoc model of reproductive success $R S$ taking into account the variation with colony size in family size at fledging and in the probability of whole-colony failure. See method section for details. Dotted lines are confidence intervals computed by sampling 1000 times in the estimated variation of models parameters (Tables $2 \& 3$ ). 
Péron 23

\section{Figures}

Fig. 1

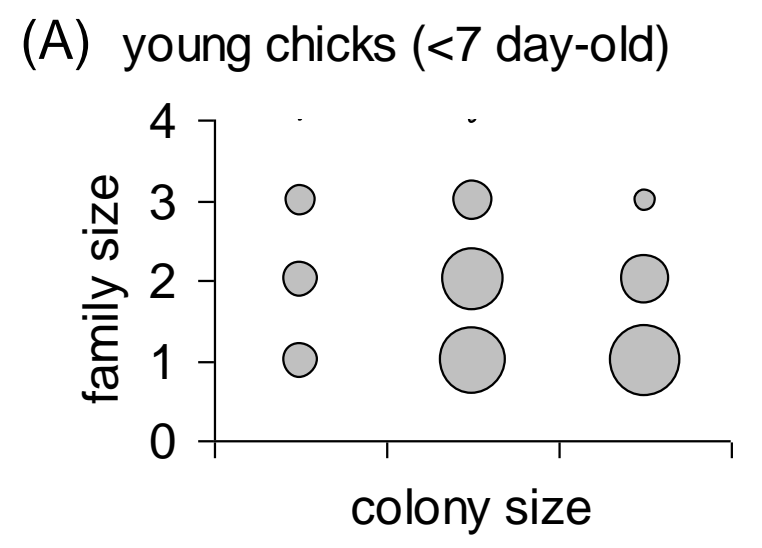

(B) old chicks (>24 day-old)

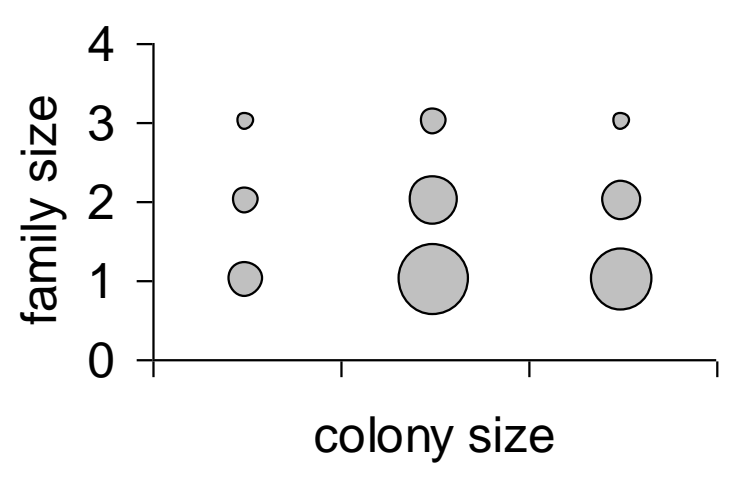


Péron 24

Fig. 2

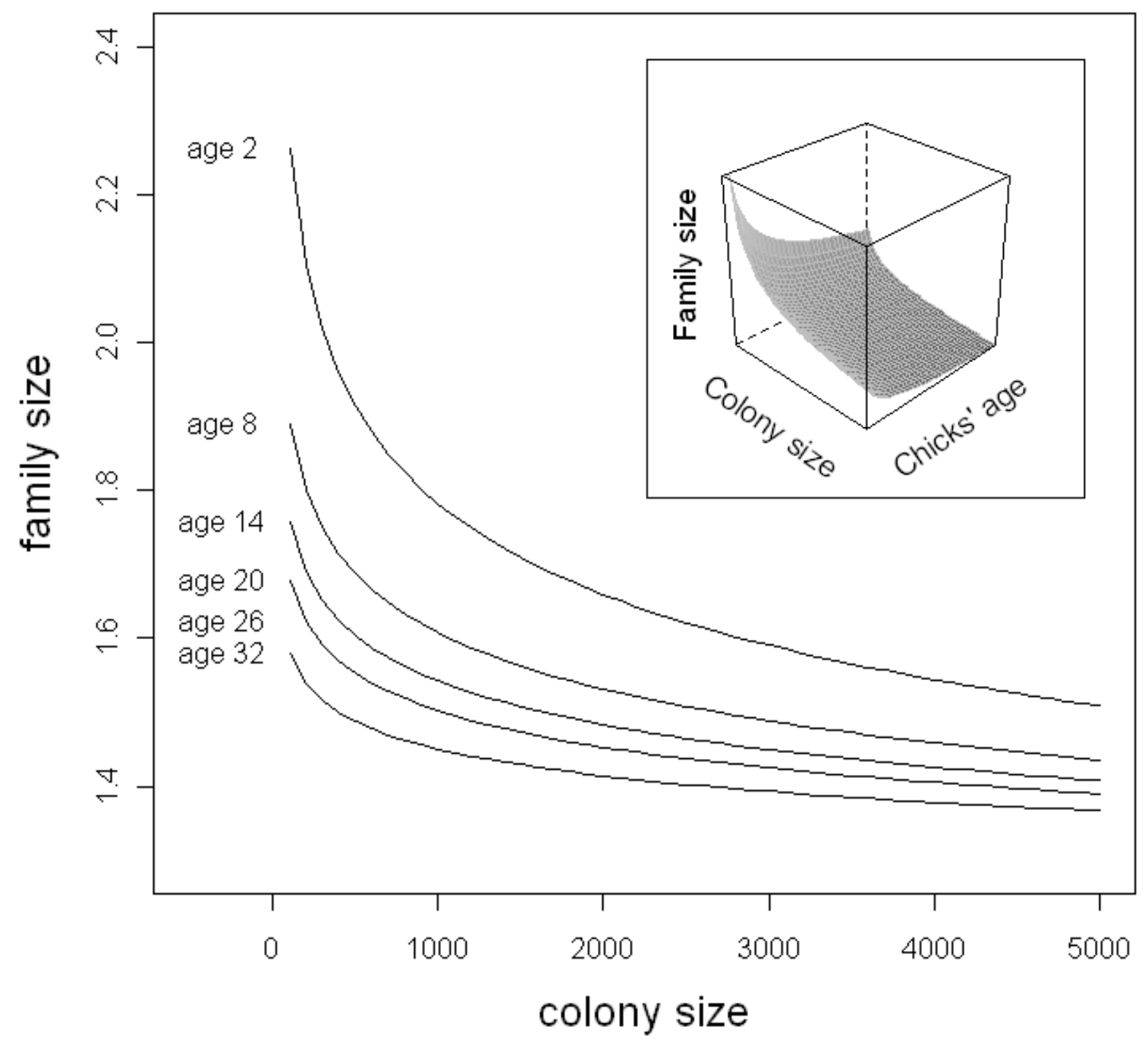


Péron 25

Fig. 3

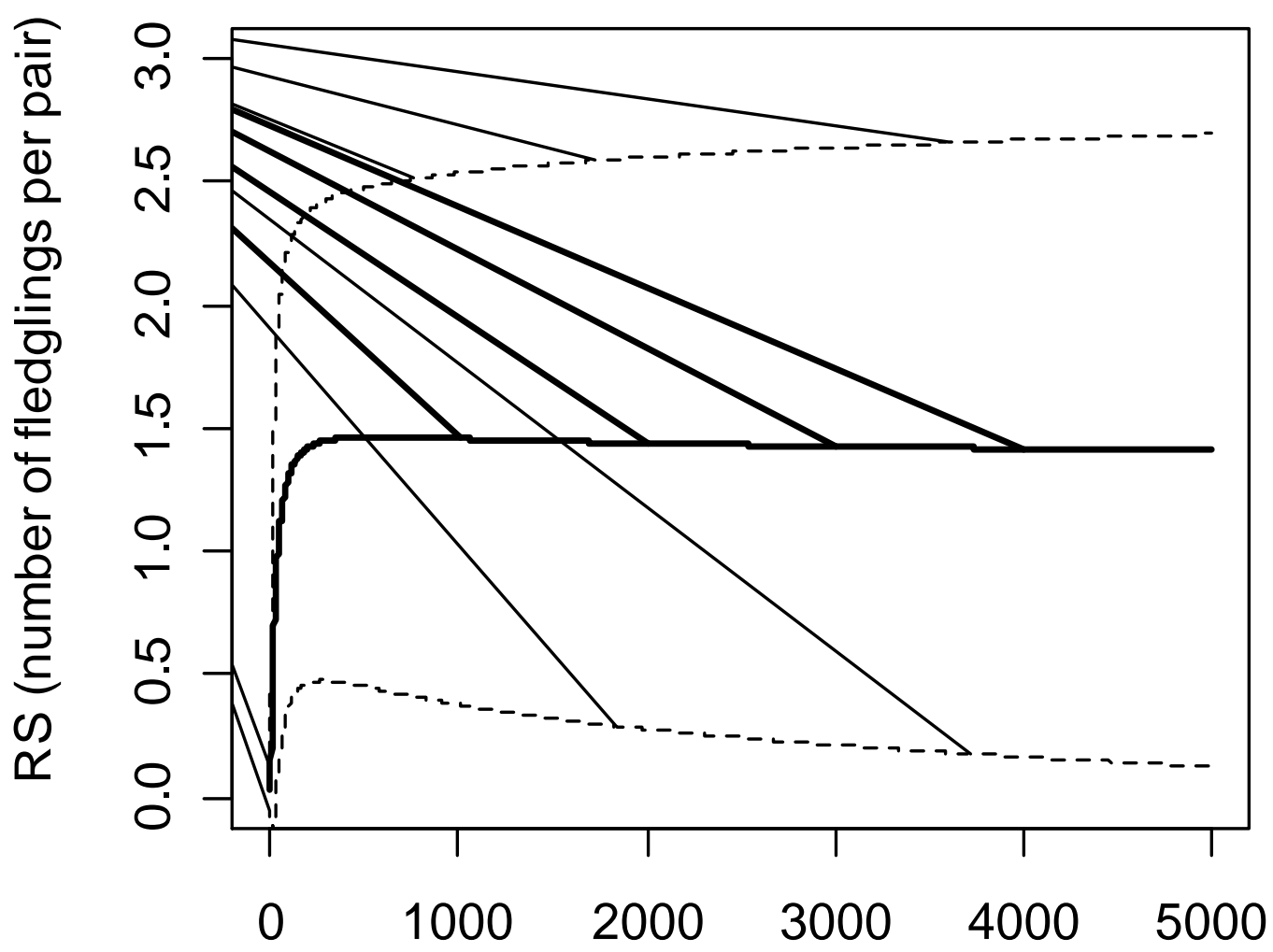

Colony size 
Péron 26

\section{Tables}

Table 1: Proportion of failed (0), low-success (1), and high-success (2) colonies across four ranges of colony size.

\begin{tabular}{lrrr}
\hline Size $\backslash$ success & 0 & 1 & 2 \\
\hline $0-15$ & 0.80 & 0.12 & 0.08 \\
$16-200$ & 0.22 & 0.44 & 0.34 \\
$201-1000$ & 0.03 & 0.24 & 0.73 \\
$>1000$ & 0.00 & 0.06 & 0.94 \\
\hline
\end{tabular}

Colony size is the number of pairs. 
Table 2: Final GLMM for family size.

\section{Random effects}

SD

Parent's identity

0.053

Year

0.006

Residual

0.20

Between-year autoregression coefficient $\quad 0.57$

\begin{tabular}{lll}
\hline & \multicolumn{2}{l}{ Fixed effects } \\
\hline & Estimates & $95 \%$ CI \\
\cline { 2 - 3 } Chicks' age & -0.24 & $-0.49 ; 0.007$ \\
Colony size & -0.12 & $-0.19 ;-0.055$ \\
Colony size $\times$ Chicks' age & 0.024 & $-0.008 ; 0.056$ \\
\hline
\end{tabular}

The dataset is constituted of 1255 records of family size from 966 parents, for 31 years and 10 colonies ranging from 56 to 5000 pairs. Chick's age and colony sizes are log-transformed. SD refers to random effects' estimated standard deviation value. CI refers to fixed effects' confidence interval. 
Péron 28

Table 3: Final GLMM for colony failure probability.

\begin{tabular}{lll}
\hline \multicolumn{3}{c}{ Random effects } \\
\hline \multirow{3}{*}{ Year } & SD \\
\cline { 2 - 3 } Residual & 0.40 \\
& 0.82 & \\
\hline \multicolumn{3}{c}{ Fixed effects } \\
\hline \multirow{3}{*}{ Colony size } & \multicolumn{2}{l}{ Estimate } \\
\cline { 2 - 3 } & & \\
\hline
\end{tabular}

The dataset is constituted of 527 records of colony success for 31 years and 10 colonies ranging from 56 to 5000 pairs. Colony sizes are log-transformed. 